\title{
IX. Bildet sich Methaemoglobin in dem Blute lebender Thiere bei tödtlicher Vergiftung mit chlorsaurem Kali?
}

Kurze Mittheilung von Dr. Hormann Lenhartz, Docent für innere Medicin in Leipzig.

Unter obiger Ueberschrift veröffentlicht Prof. Bokai, in No. 42 dieser Wochenschrift, das Ergebniss seiner an Kaninchen ausgeführten Vergiftungs-Versuche und gelangt zu der Annahme, dass die Methaemoglobin-Bildung im lebenden Blute des Kaninchens nicht nachweisbar, zum mindesten nichtals Todesursache aufzustellen ist.

Auf Grund einer grösseren Reihe von ähnlichen, mit einer einzigen Ausnahme indess an $\mathrm{Hu}$ den angestellten Versuchen, bin ich dem entgegen in der Lage, den Beweis zu führen, dass die Methaemoglobin-Bildung bei diesen Thieren unter dem Einfluss toxischer Gaben des Natriumchlorats sich thatsächlich im lebenden Blute vollzieht, und dass bei dem Fehlen jeder weiteren Storrung, lediglich diese schwere Blutveränderung als Causa mortis heranzuziehen ist.

Nachdem ich bereits im Februar d. J. die Beobachtung gemacht hatte, dass bei einem vergifteten Thier schon 1 Stunde vor dem Tode in den entnommenen Blutproben das Methaemoglobin sich fand, suchte ich dasselbe (bei einem ähnlich angeordneten Versuch) im lebenden Blut direkt spektroskopisch aufzufinden. Am 28. Mai gelang es mir zum ersten Male die Thatsache zu beobachten, dass bereits $3 / 4$ Stunden vor dem durch chlorsaures Natron herbeigeführten Tode im lebenden, in dem Ohrkreislauf circulirenden Blute der Absorptionsstreif. im Roth auftrat. Bei einem späteren, am 17. Juli d. J. beendeten Versuche hatte ich Gelegenheit, dem gerade anwesenden Herrn Prof. E. Wagner das bez. spektroskopische Bild zu demonstriren; auch dieses Thier ging erst 1 Stunde nach dem (zuerst beobachteten) Auftreten des Absorptionsstreifens za Grunde.

Gleich Bokai habe ich am Kaninchenohr den Streifen vergeblich gesucht; das wird durch andere, später zu erörternde Umstände begründet sein.

Jedenfalls aber muss ich nach meinen Versuchen an Hundeu die von Bokai aufgeworfene Frage bejahen. In eiver demnächst erscheinenden Arbeit über experimentelle Untersuchungen mit den chlorsauren Salzen wird diese Frage ausführlich behandelt. 